\title{
Da câmara subjetiva à falsa objetividade das imagens no cinema: apontamentos sobre duas experiências limite
}

\section{Mirian Tavares ${ }^{1}$}

\begin{abstract}
Resumo: Através da análise de um aspeto morfológico do dispositivo cinematográfico, a câmara subjetiva, procuro apresentar modelos divergentes de utilização do cânone e processos alternativos de projeção/identificação pela imagem. O recurso à câmara subjetiva está associado, geralmente, a momentos de grande tensão quando se espera uma maior aderência do espectador ao ecrã : vemos através dos olhos das personagens e assim aumenta a sensação de envolvimento, e de presença, do filme em nós e de nós mesmos dentro do espaço diegético. Raramente a câmara subjetiva é / foi utilizada durante todo o filme, apagando assim o corpo das personagens do ecrã, porque se sabe que o mundo das imagens é o mundo da sedução e do reconhecimento que se dá pelo corpo projetado, e idealizado, que se (im) põe ao nosso olhar. Não nos podemos esquecer devque a imagem do ecrã é um constructo ideológico que faz parte da tradição artística ocidental. Os artistas do início do século XX pretenderam desmistificar o cânon e demonstrar que tudo na arte era sempre fruto de uma construção. Este modelo de representação, negado pelas vanguardas, foi absorvido pela fotografia e pelo cinema e, apesar dos discursos divergentes que hoje atravessam o discurso canônico ocidental, ainda perduram reproduções e replicações deste modelo, dentro e fora do espaço europeu.
\end{abstract}

Palavras-chave: Imagem; Cânone; Representação; Câmara Subjetiva

\begin{abstract}
Through the analysis of a morphological aspect of the cinematographic device, the subjective camera, I try to present divergent models of canon use and alternative processes of projection / identification by the image.The use of the subjective camera is usually associated with moments of great tension when the viewer is expected to be more closely connected to the screen: we see through the eyes of the characters and thus increase the sense of involvement and presence of the film in us and of ourselves within the diegetic space. Rarely is the subjective camera used throughout the film, thus erasing the body of the screen characters because it is known that the world of images is the world of seduction and recognition given by the projection. We must not forget that the screen image is an ideological construct that is part of the Western artistic tradition. Artists of the early twentieth century sought to demystify the canon and demonstrate that everything in art was always the result of a specific idea. This model of representation, denied by the avant-gardes, has been absorbed by photography and cinema, and despite the divergent discourses that now cross Western canonical discourse, reproductions and replications of this model still exist within and outside the European space.
\end{abstract}

Keywords: Image; Canon; Portray; Subjective Camera

1 Professora Associada da Universidade do Algarve. Com formação académica em Ciências da Comunicação, Semiótica e Estudos Culturais,doutorou-se em Comunicação e Cultura Contemporâneas, na Universidade Federal da Bahia. E-mail: miriantavar@gmail.com 


\section{Introdução}

Hugo Munsterberg, que escreveu uma obra pioneira sobre o cinema, perguntava-se em 1916 se o cinema traria um contributo próprio estético e artístico, diferente daquele que era inerente ao teatro. A resposta a esta inquietação é dada ao longo do livro:o cinema cria leis próprias, baseadas numa estética particular e de todos os meios narrativos anteriormente criados pelo homem, é o primeiro que efetivamente incorpora, na sua conceção, os mesmos mecanismos que regulam a perceção humana. Ou seja, o cinema resulta porque estruturalmente funciona de maneira semelhante ao nosso aparelho percetivo: vemos filmes como percebemos o mundo à nossa volta, usando os mesmos mecanismos mentais.

A gramática griffthiana, que influenciou toda a produção cinematográfica norte-americana e, em certa medida, a mundial, era baseada no mecanismo de identificação. A imagem de Lilian Gish, atriz fetiche do realizador, em closeup, fascinou multidões. O closeup, tema recorrente na teoria feminista do cinema, que analisa assim a erotização do rosto feminino no cinema clássico de Hollywood, faz parte do dispositivo cinema desde que Edwin S. Porter, em 1903, nos apresenta um homem a atirar sobre a plateia no filme The Great Train Robbery, considerado um dos primeiros filmes do cinema que organiza, de forma consciente, o relato, e que utiliza, mesmo que de maneira primária, os princípios da montagem. No caso do filme de Porter, o closeup era uma espécie de "extra”, que poderia ser exibido no princípio ou no fim do filme e que, de facto, não pertencia ao relato. Não é o que ocorre com o closeup de Lilian Gish, no filme Intolerance, de 1916, que pertencem à diegese e que inauguram uma estética que vai perdurar no cinema clássico, tornando-se uma marca registada dos filmes produzidos em Hollywood.

O rosto, destacado do fluxo narrativo, provoca stasis e cria uma retórica do não-movimento, uma espécie de pequena morte, um instante de prazer, que justifica o impulso à escopofilia e reitera o ponto de vista marcadamente masculino deste tipo de cinema. Apesar da predominância do modelo hollywoodiano, existe uma cinematografia divergente, muitas vezes periférica, que seguiu outros caminhos, na tentativa de converter o cinema num lugar possível da poesia. $\mathrm{O}$ confronto entre estes dois modos de se fazer e de se pensar o dispositivo cinema pode ser desvelado através da proposta de leitura de dois filmes, produzidos em contextos e tempos diversos, mas que utilizam como elemento morfológico principal, a câmara subjetiva, que nega ao espectador a 
presença no ecrã do rosto dos protagonistas.

\section{A dama do lago}

Em 1947, um filme de Robert Montgomery, baseado na obra de Raymond Chandler, The Lady in the lake, provocou perturbação no universo do cinema clássico, cuja tónica sempre esteve assente na criação de um discurso da realidade e da projeção. The Lady in the lake é um filme noir e o realizador decidiu transpor a história para o ecrã utilizando o mesmo estilo da escrita de Chandler: o texto narrado em primeira pessoa e com uma personagem/narrador omnisciente.

O protagonista do filme, o detetive Philip Marlowe, só nos é mostrado muito rapidamente no princípio e no final do filme e em breves frames, através de espelhos ou do reflexo do vidro de uma porta. O filme, como o livro, segue a tendência da literatura policial hard boiled, herdeira de uma tradição que remonta aos Crimes da Rua Morgue de Edgar Allan Poe. Essaé a primeira experiência realizada em Hollywood que leva ao extremo o papel da câmara subjetiva: vemos através dos olhos do detetive e só vemos o que ele vê. As mãos dele aparecem algumas vezes em cena e a ideia do realizador era permitir que o espectador sentisse estas mãos como suas. O que não aconteceu. Aliás, o filme foi um fracasso de bilheteira apesar de toda a promoção que foi feita à sua volta. Montgomery não percebeu que, para criar a identificação com as personagens dos ecrãs, é preciso mostrá-las, exibir evidências que, de alguma maneira, elas são de carne e osso como nós. Jean-Louis Comolli, ao falar do cinema de John Cassavetes afirma: "El cine es un arte ambicioso. Lo que desea es que el adentro se libre en el afuera. Filmar el exterior para descubrir el interior (...)" (2007, p. 153). Ora, o processo de filmagem de The Lady in the lake faz precisamente o contrário: filma o interior para que se veja o exterior. Ou seja, não vemos a superfície do corpo do ator, só vemos o seu olhar, a direção que ele toma ou o seu ângulo de visão. Como se estivéssemos dentro da sua cabeça. Mas, conforme Comolli, para entrar no interior da personagem é preciso personificá-la, dar corpo ao olhar.

Anos mais tarde, em 1975, a cineasta e escritora Marguerite Duras realiza o seu IndianSong, cujo argumento provém de uma peça nunca encenada da autora. O filme conta uma história de amor que poderia ser banal, não fosse a opção que Duras faz de narrar visualmente os diálogos, que se ouvem fora de campo, mas que quase nunca são mostrados a serem enunciados pelas personagens. Sentimo-nos como alguém que 
ouve uma conversa que não deveria ouvir, como alguém que, inopinadamente está no lugar errado e participa, à distância, do drama que se desenrola, ao mesmo tempo perto e distante de nós. O vazio e o tédio da relação entre a mulher e o marido e a paixão culpada, mas permitida, entre a mulher e o amante, são representados duplamente: primeiro pelo texto, que nos conta a história através das personagens cujos diálogos são quase monólogos; e segundo, pelo vazio do próprio ecrã, pelo papel da câmara que, neste filme, parece estar sempre fora do sítio.

O filme, rapidamente, transformou-se em obra de culto, sobretudo porque relembrava, anos depois, o clima de $O$ ano passado em Marienbad, obra de Alain Resnais, baseado num guião original de Alain Robbe-Grillet. Como Duras, Resnais não nos oferece um filme de fácil degustação. A narrativa não segue os meandros, nem as regras, impostas pelo cinema clássico, rompendo o fluxo espácio-temporal criando no espectador a sensação de desequilíbrio e de insegurança, pois neste caso ele não domina a narrativa, não sabe o que vem a seguir e muito menos consegue prever como será o final. Ambos os realizadores fizeram parte da Nouvelle Vague, a nova vaga do cinema francês, que juntamente com o neorrealismo italiano provocou roturas irreparáveis na ordem do cinema clássico norte-americano.

O filme de Montgomery apesar de profundamente inovador, pertence à lógica de produção dos estúdios e o realizador não pretendia perturbar os seus espectadores, a sua intenção era permitir que o lugar do voyeur, que todo espectador ocupa, fosse substituído pelo papel de participante ativo da ação, de personagem do filme. $\mathrm{O}$ problema é que o filme existe enquanto imagem, mesmo que o seu processo de significação seja um processo mental, os espectadores se veem não apenas na narrativa, mas precipuamente vestem a pele dos atores, habitam, ou desejam fazê-lo, os corpos que povoam o ecrã.

\section{Da perceção à identificação}

O processo de identificação no cinema dá-se através do reconhecimento de uma alteridade, o espectador ocupa o lugar do "outro": "En su parte documental- que es la marca de su nacimiento y la condición de su invención -,el cine no hace más que abrir el diafragma de una lente, la sesibilidad de una emulsión (...) a la presencia luminosa del otro, más o menos, es todo el asunto, de ese otro que viene hacia la cámara tanto como ésta va hacia él." (COMOLLI, 2007, p. 46). Para Comolli, o outro que vemos 
no ecrã, que é capturado pela câmara, é um corpo que reconhecemos como diverso e igual. E é na associação entre o que vê e o que é olhado, na crença do milagre efetuado pela luz que imprime o real no fotograma, que se estabelece uma relação de poder. $O$ espectador ocupa, normalmente, o lugar do morto, não é ele quem conduz a narrativa mas é sim conduzido por ela.

O número de espectadores que o cinema norte-americano conseguia atrair nos seus primórdios foi crescendo, à medida que crescia também a capacidade deste dispositivo de se tornar mais próximo do real, e paradoxalmente, mais distante. O som sincrónico e mais tarde o aparecimento da cor, ajudaram o cinema a aproximar-se do mundo extra-ecrã transformando os seus artifícios paradoxalmente em elementos de realidade, ou seja, cada novo efeito, ajudava os realizadores a criarem no público a sensação efetiva de estar diante de uma janela aberta para o mundo. Ao contrário daquilo que as Vanguardas Históricas preconizaram, ou realizaram com o cinema, os filmes caminham em direção à normatização e à organização da mise enscène a favor da duplicação do real e não da criação de novas possibilidades de leitura do mundo.

Os filmes destinados ao grande público (mesmo na era digital, que permite uma maior plasticidade às imagens e maior versatilidade na montagem, através da edição) continuam a apostar na narrativa do séc. XIX e na vertente realista do cinema, entendendo este realismo como a capacidade que o dispositivo tem de dar ao espectador a ilusão de espreitar, através de uma janela, que é o ecrã, um mundo possível, um duplo da sua própria realidade, ou uma alteridade desejada e desejável.

O antropólogo MassimoCanevacci vai explorar a relação do cinema com a psique humana empregando não mais as teorias freudianas/lacanianas, optando antes pela tese do duplo vínculo postulada por Gregory Bateson. "O objeto da teoria do duplo vínculo estabelece um tecido de mensagens que só têm um significado graças ao contexto." (Canevacci, 1990:41). A mensagem, no cinema, existe dentro de um contexto que podemos ampliar até chegarmos a um metacontexto que implica o "efeito cinema", descrito por Baudry, a estrutura de realização do filme que reproduz mecanismos do nosso aparelho percetivo, conforme Munsterberg e a associação do cinema, desde os primórdios, à fotografia que imprimia, nas imagens projetadas, uma ideia de realidade. No caso do contexto, podemos enumerar o reconhecimento da estrutura dramatúrgica, que sofreu pequenas variações desde a invenção da gramática do cinema por Griffith, bem como o embodyment suscitado pela visão dos corpos exibidos no ecrã. Assim, o espectador reconhece a estrutura mecânica, formal e dramática dos filmes, podendo 
desta forma desenvolver com eles uma relação de duplo vínculo.

De acordo com a teoria desenvolvida por Canevacci, o cinema é o meio perfeito para se experimentar o modelo do duplo vínculo proposto por Bateson, pois o espectador vivencia como suas as imagens que aparecem no ecrã, ao mesmo tempo que está consciente de que aquela não é a sua realidade, mas uma existência que não lhe pertence e que dificilmente seria concretizável no seu espaço societal. Os estudos que Bateson desenvolveu com esquizofrénicos e com golfinhos foram, mais tarde, usados para analisar diversas relações no seio da família, sobretudo no par mãe/filho ou filha. No fundo a ideia de duplo vínculo necessita de uma "vítima", o filho (a) e de um perpetrador, a mãe. A criança percebe muitas vezes que a mãe a manda dormir porque quer estar sozinha, o que desperta em si um sentimento de rejeição. Ao mesmo tempo, interpreta a mensagem da mãe literalmente, indo dormir, porque é uma necessidade e não porque a mãe já não a quer por perto. A criança fica assim vinculada à mãe que transmite mensagens de "duas ordens, "uma das quais nega a outra"” (CANEVACCI, idem: 39). Para evitar o sentimento de perda provocado pela primeira interpretação, a criança escolhe enganar-se, discriminando de forma errada os sinais que a mãe emite. Em casos extremos, o dos esquizofrénicos, a criança perde a capacidade de "comunicar sobre a comunicação, pelo que se torna incapaz de determinar o verdadeiro significado do que os outros dizem e de exprimir o que ela mesma entende (...)". (idem: 40).

No cinema, o espectador ocupa o lugar da criança que se engana a si mesma para obter prazer do filme e não se sentir frustrado por perceber que, claramente, o que tem à sua frente é uma mentira e uma impossibilidade. Assim, reconhecendo o contexto em que se encontra, responde positivamente ao "efeito-cinema" deixando-se enredar pelas emoções simuladas no ecrã e vivenciando-as como se fossem dele.

\section{O não-discurso do cinema}

No caso do cinema, o modelo canónico é aquele aperfeiçoado por Griffith e reiterado ao longo da história do séc. XX, através dos closesups das estrelas que povoaram, e que ainda povoam, o imaginário mundial, gerando modelos desejosamente especulares, mas que são frustrados quando confrontados com a realidade de cada espectador ou do público em geral. O espectador, como a criança de Bateson, sofre por perceber que o que vê não existe, mas aparentemente está no mundo dos possíveis, porque parece real, porque reproduz mimeticamente os corpos e porque todo o cine- 
ma, seja documental ou ficção, é sempre um documento de um corpo que foi fotografado ou gravado, que esteve, em dado momento, na presença da câmara que o captou.

A experiência limite do filme The Lady in the lake foi repetida, diversas vezes, com algum êxito, no cinema hollywoodiano: o uso da câmara subjetiva, ocupando o lugar do sujeito/personagem, aparece em filmes de terror, aumentando assim a sensação de imersão e excitando ainda mais a imaginação do espectador, sensações que este género deseja proporcionar. Nenhuma outra experiência, no entanto, foi tão longe como o filme de Montgomery porque o cinema da "identificação" percebeu rapidamente que precisa de um corpo para que o efeito especular se realize.

\section{Viajo porque preciso}

Em 2009, dois cineastas brasileiros repetem a experiência de Montgomery e realizam um filme cujo personagem é o que vê, é o que narra, é o que conduz a história, mas que nunca é visto. O filme, Viajo porque preciso volto porque te amo, é uma espécie de road movie que se passa no Nordeste do Brasil, dando-nos a ver o interior quase desconhecido desta parte do país, bem como apresenta uma série de personagens que são, ao mesmo tempo, parte da ficção e habitantes das cidades e vilarejos por onde passa o protagonista numa viagem que, a princípio, parece ser apenas de trabalho mas que logo se revela uma viagem simbólica e circular, que reflete uma tentativa impossível de fuga que a personagem, primeiro inconscientemente e, mais tarde, bastante consciente, se propõe realizar.

Ao contrário do filme noir, The lady in the lake, inspirado na escrita de Raymond Chandler, Viajo porque preciso (...) é quase um filme documental dado a pouca qualidade da captação de algumas imagens e do som, que às vezes é feito em tomadas diretas, o que dificulta ao público a perceção do que se diz, mas que ajuda a amplificar a impressão de realidade que o filme impõe. José Renato, o protagonista, é geólogo e foi enviado para realizar uma pesquisa, que o obriga a atravessar todo o sertão nordestino. A sua missão é avaliar o possível percurso de um canal que será feito, desviando as águas do único rio caudaloso da região. Ouvimos a sua voz a conduzir-nos cada vez mais para dentro de um espaço desconhecido e quase desabitado, ao mesmo tempo em que o acompanhamos na sua carrinha, pelas estradas, ouvindo a rádio que ele ouve e sendo testemunhas das suas reflexões.

Karim Aïnouz e Marcelo Gomes, os autores, realizaram esta obra a partir de 
outro filme que estavam a produzir, motivados por suas próprias descobertas no e do sertão nordestino e com restos de cenas que gravaram e que acabaram por não utilizar. José Renato, o geólogo que acompanhamos durante toda a diegese, fala-nos do que vê, sem que sua fala tenha um caráter reiterativo ou de ratificação do visto; o que ele faz é dar-nos a ver, através do seu olhar, personagens e lugares que perturbam, e que enriquecem, a sua viagem. A câmara é subjetiva e nunca vemos, nem mesmo através de reflexos, a personagem única e principal. O cinema, neste caso, consegue simular a ideia de documento, o que é exibido é o que o geólogo capta no seu percurso, mas esquecemo-nos que alguém, que não está na diegese, capta a imagem da personagem e dá-nos a ver o que ele, aparentemente, vê. Conforme Emile Benveniste, ao falar do cinema em geral, "Os acontecimentos são dispostos como se estivessem se produzindo à medida que aparecem no horizonte da história. Ninguém fala aqui. Os acontecimentos parecem se narrar a eles próprios." (1966, p. 241). Neste filme, sentimos de maneira mais intensa esta presença, ou melhor, esta ausência do "grande narrador" extra-diegético que constrói a narrativa. Participamos da construção da própria história, ou assim o sentimos, desde que a carrinha de José Renato aparece no ecrã e desde que ouvimos a sua voz.

O filme brasileiro e o norte-americano não são comparáveis. Não só pela distância espácio-temporal que existe entre ambos, bem como pelas estruturas de produção e, finalmente, pela intenção dos autores. O filme de Montgomery experimentava num território minado pela ordem canónica de formas estritas de representação; o filme de Aïnouz e Gomes pertence ao espaço mais plástico e permissivo do cinema experimental. A história que The Lady in the lake nos conta é convencional na sua estrutura narrativa, apesar de não o ser na sua forma, por isto o incômodo causado na altura da sua exibição, e a receção fria do público que já estava acostumado a um modelo estabelecido e tinha muita dificuldade em desfrutar perversamente, neste filme, do duplo vínculo que o cinema propõe, negando e afirmando a realidade daquilo que mostra.

No caso de Viajo porque preciso (...) o público já acompanhou a destruição e a reinvenção do cânone e também já se adaptou aos novos dispositivos digitais que permitem uma edição mais sincopada e veloz das imagens; por outro lado, o filme se apresenta a partida como não convencional, como um quase-documentário, o que permite mais facilmente a adesão à sua forma e ao uso que faz da câmara subjetiva, pois subsumimos que no cinema documental o autor deve estar presente o mínimo possível, deixando que a história, que os eventos se narrem a si próprios. Por outro lado, 
enquanto no filme norte-americano assistimos a uma história fechada, teleológica e previsível, no filme brasileiro assistimos a um percurso, que se desenrola diante dos nossos olhos, que nos mostra um ambiente em que a maioria de nós não se revê, mas consegue que o público se reveja naquilo em que o filme se transforma: uma metáfora do vazio, dos descaminhos, das histórias de amor com finais infelizes, da errância humana sobre a terra e, internamente, dentro de si mesma, à procura de respostas e daquilo que é o fito último de cada um: ir ao encontro de uma felicidade possível.

Viajo porque preciso (...) aproxima-se mais da proposta de Duras que tentou, com IndianSong, ao criar um filme atemporal, que representasse não apenas aquela história de amor, mas todos os triângulos amorosos do mundo, todas as situações de angústia provocadas pela manutenção de uma relação que se sabe, à partida, condenada. O processo de identificação nestes filmes ocorre por causa dos princípios que eles enunciam, e não pelas histórias que contam. Neste caso, o corpo da personagem, ou das personagens, pode estar ausente porque é preenchido pelo corpo do espectador que sente como e através do filme.

Assim temos que a relação de identificação com o cinema não se dá apenas através da (falsa) especularidade dos corpos, mas também ocorre quando um filme apela a sentimentos arquetípicos, propondo ao espectador um lugar ativo na história. O que só ocorre, verdadeiramente, no cinema que podemos chamar de "divergente", de não canónico. Mas este tipo de cinema ainda atinge um público pequeno diante dos muitos milhões que consomem o modelo norte-americano e que, como tal, continuam a desfrutar do gozo perverso do duplo vínculo, do saber-se não representado mas continuar acreditando que se vê no ecrã, replicando comportamentos e modelos que ocultam uma ideologia específica e que suscita, paulatinamente, a normatização dos comportamentos e cria uma sensação real, embora distorcida, de pertença.

\section{Referências}

DUDLEY, Andrew. As Principais teorias do cinema. Rio de Janeiro: Jorge Zahar, 1989.

RUDOLF, Arnheim. Arte e percepção visual: uma psicologia da visão criadora. São Paulo: Pioneira, 1998

JACQUES, Aumont; Michel, Marie. Dicionário teórico e crítico de cinema. Campinas:Papirus, 2003

BARTHES, Roland et al. Psicanálise e cinema. Lisboa: Relógio D’Água, 1984. 
BAUDRY, Jean-Louis. Ideological effects of the basic cinematographic apparatu. In Film Quarterly, v. 28, n.2, 1974-1975.

BENVENISTE, Émile. Problèmes de linguistique générale, v. I. Paris : Gallimard, 1966.

BURCH, Noël. El tragaluz del infinito. 3 ed., Madrid :Cátedra, 1995.

CANEVACCI, Massimo. Antropologia da Comunicação Visual. São Paulo : Brasiliense, 1990

CARRIÈRE, Jean-Claude. A linguagem secreta do cinema. Rio de Janeiro: Nova Fronteira, 1995 .

COMOLLI, Jean-Louis. Ver y Poder - La inocencia perdida: cine, televisión, ficción, documental, Buenos Aires: Aurelia Rivera, 2007.

CRARY, Jonhatan. In CHARNEY, L.; SCHWARTZ, V. R. (Orgs.), O Cinema e a invenção da vida moderna. São Paulo: Cosac\&Naify, 2001.

DEBRAY, Régis. Vida e Morte da Imagem. Petrópolis: Editora Vozes, 1994.

DONDIS, Donis A. Sintaxe da Linguagem Visual. São Paulo: Martins fontes, 1999.

EISENSTEIN, Sergei. Teoria y tecnica cinematograficas. 4 ed. Madrid: Ediciones Rialp, 1989.

MAUERHOFER, Hugo.A Psicologia da Experiência Cinematográfica”. In XAVIER, Ismail (Org.), A Experiência do Cinema. Rio de Janeiro: Graal, 1983.

MUNSTERBERG, Hugo. The Photoplay - A Psychological Study. The Project Gutenberg, 1916. Disponível em: <http://www.gutenberg.org/files/15383/15383-h/15383-h. htm>. Acesso em: 19 abr. 2019.

TAVARES, Mirian Nogueira. Cinema digital: novos suportes, mesmas histórias. In $A R S$, v. 6, n. 12, p. 35-47,2008. Disponível em: < http://www.scielo.br/scielo.php?script=sci_arttext\&pid=S1678-53202008000200004 >. Acesso em: 19 abr. 2019.

XAVIER, Ismail. O Cinema no século. Rio de Janeiro: Imago, 1996. 